\title{
Review Article \\ Osthole: A Review on Its Bioactivities, Pharmacological Properties, and Potential as Alternative Medicine
}

\author{
Zhong-Rong Zhang, Wing Nang Leung, Ho Yee Cheung, and Chun Wai Chan \\ School of Chinese Medicine, The Chinese University of Hong Kong, Li Wai Chun Building G08, Shatin, New Territories, Hong Kong \\ Correspondence should be addressed to Chun Wai Chan; fcwchan@cuhk.edu.hk
}

Received 13 May 2015; Accepted 28 June 2015

Academic Editor: Ilaria Lampronti

Copyright (C) 2015 Zhong-Rong Zhang et al. This is an open access article distributed under the Creative Commons Attribution License, which permits unrestricted use, distribution, and reproduction in any medium, provided the original work is properly cited.

\begin{abstract}
This paper reviews the latest understanding of biological and pharmacological properties of osthole (7-methoxy-8-(3-methyl2-butenyl)-2H-1-benzopyran-2-one), a natural product found in several medicinal plants such as Cnidium monnieri and Angelica pubescens. In vitro and in vivo experimental results have revealed that osthole demonstrates multiple pharmacological actions including neuroprotective, osteogenic, immunomodulatory, anticancer, hepatoprotective, cardiovascular protective, and antimicrobial activities. In addition, pharmacokinetic studies showed osthole uptake and utilization are fast and efficient in body. Moreover, the mechanisms of multiple pharmacological activities of osthole are very likely related to the modulatory effect on cyclic adenosine monophosphate (cAMP) and cyclic adenosine monophosphate (cGMP) level, though some mechanisms remain unclear. This review aims to summarize the pharmacological properties of osthole and give an overview of the underlying mechanisms, which showcase its potential as a multitarget alternative medicine.
\end{abstract}

\section{Introduction}

Osthole (also known as osthol), 7-methoxy-8-(3-methyl-2butenyl)-2H-1-benzopyran-2-one, is a natural coumarin first derived from Cnidium plant (Figure 1). High content of osthole is found in the mature fruit of Cnidium monnieri (Fructus Cnidii), which is commonly applied in clinical practice of Traditional Chinese Medicine (TCM) (Figure 2), while it is also widely found in other medicinal plants including Angelica, Archangelica, Citrus, Clausena. Fructus Cnidii strengthens immune system and improves male function, relieving rheumatic pain and eliminating dampness; most of these medicinal properties are considered to attribute to one of its major bioactive components, osthole [1, 2]. Modern researches have suggested that osthole exhibits antioxidant, anticancer, anti-inflammatory, and immunomodulatory properties $[1,3,4]$. With multiple bioactivities of osthole reported, developing osthole and derivatives as potential multitarget drug should be encouraged. Therefore, it is meaningful to summarize the pharmacological and biological researches on this coumarin, to review the mechanisms behind the effects and get a comprehensive picture of its miscellaneous functions.

\section{Biological and Pharmacological Activities of Osthole}

2.1. Nootropic and Neuroprotective Effect. The benefits of osthole and Fructus Cnidii (FC) extract on nervous system have been investigated in recent years. Osthole regulates ion channels and G protein-coupled receptor (GPCR) activities influencing neuronal and neuroendocrine function. Evidence suggested that osthole blocked L-type $\mathrm{Ca}^{2+}$ channel and $\mathrm{Na}^{+}$ channels in mouse neuronal cells $[5,6]$. Osthole increased the affinity of thyrotropin-releasing hormone (TRH) receptor (one of GPCR), hence decreasing the binding of TRH to its receptor and suppressing TRH-evoked production of triphosphoinositol $\left(\mathrm{IP}_{3}\right)$ and mobilization of sequestered $\mathrm{Ca}^{2+}$ in rat pituitary $\mathrm{GH}_{4} \mathrm{C}_{1}$ cells [7]. In addition, Wang et al. examined the effect of osthole and imperatorin (another coumarin isolated from FC) on glutamate release from rat hippocampal synaptosomes. The results suggested that both chemicals facilitated 4-aminopyridine- (4-AP-) evoked glutamate release by activating $\mathrm{N}$-and $\mathrm{P} / \mathrm{Q}$-type $\mathrm{Ca}^{2+}$ channel through a signaling cascade involving protein kinase $\mathrm{C}$ (PKC) [8]. Lin et al. then suggested osthole-facilitated glutamate release was 


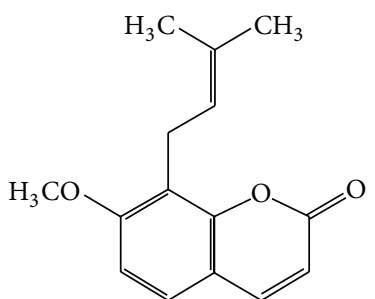

FIGURE 1: Chemical structure of osthole, the principle component of Cnidium monnieri.

related to increased synaptic vesicle availability for exocytosis [9] and to activation of cGMP/PKG-dependent pathway [10]. Osthole was also found to reduce acid-sensing ion channel 3 (ASIC3) expression in rat dorsal root ganglion, which may contribute to its relieving chronic pain from lumbar disc herniation [11]. Moreover, Luszczki et al. reported that osthole showed anticonvulsant effect in maximal electroshock seizure models, suggesting its potential in seizure treatment $[12,13]$. Osthole was identified as a modulator of the neurotransmitter gamma-aminobutyric acid $(\mathrm{GABA})_{\mathrm{A}}$ receptor in vitro, which provided a possible mechanism explaining such antiseizure effect $[14,15]$.

On the other hand, osthole exhibited neuroprotective effects against neurodegeneration in both in vitro and in vivo experimental models. Pretreatment of osthole showed significant protective effect on viability of $\mathrm{PC} 12$ cells exposed to neurotoxin $\mathrm{MPP}^{+}$, an in vitro model of Parkinson's disease [16]. Moreover, multiple evidences have demonstrated the protective effect of osthole on alleviating brain damage and improving neurobehavioral functions caused by both chronic [17] and acute [18-20] ischemia due to its antioxidative and antiinflammatory properties, through mitogen-activated protein kinase (MAPK) pathway by prolonged activation of ERK1/2 and suppression of JNK activity [20]. Osthole has also been suggested as a promising herbal component for memory loss therapy [21]. Animal experiments have been conducted in aluminium chloride- $\left(\mathrm{AlCl}_{3}-\right)$ induced acute senile model [22] and scopolamine-induced amnesia model [23], and results from both studies demonstrated ameliorating effect on memory impairment. In addition, studies demonstrated that osthole was also effective in treating traumatic brain injury by significantly reducing neurological deficits, cerebral edema, and hippocampal neuron loss [24], as well as relieving spatial performance deficits in scopolamine- (SCOP-) treated or ovariectomized (OVX) rats [25], and attenuating autoimmune encephalomyelitis in mice [26].

2.2. Osteogenic Activity. Bone modeling effect is one of the bioactivities osthole showing most promising therapeutic potential. Plenty of in vitro studies have shown that osthole and coumarin extract from FC promoted proliferation and differentiation of osteoblasts [27-30] and suppress formation and activity of osteoclasts [31,32], hence tipping the balance in favor of bone remodeling and increasing bone density, which makes osthole a potential agent for osteoporosis treatment. Findings from experiments in both ovariectomy and glucocorticoids-induced osteoporosis rat models supported that treatments with osthole and FC coumarin reduced osteoporotic bone loss [33-36] through estrogen-independent pathway, rather than phytoestrogens commonly found in medicinal herb [36]. Kuo et al. studied the mechanism of osthole-mediated cell differentiation in detail with human osteoblast MG-63 and hFOB. The results obtained after application of bone morphogenetic protein- (BMP-) 2 antagonists, p38 inhibitor, and mitogen-activated protein kinase (ERK2), respectively, indicated that BMP-2/p38 pathway was associated with early phase of osthole-induced osteoblast differentiation, whereas ERK2 was involved in later phase of cellular ossification [33]. A recent paper investigated the potential of osthole in treating and preventing bone loss due to estrogen deficiency and studied the underlying mechanism. In vitro findings revealed that osthole promoted osteoblast differentiation by activating Wnt $/ \beta$-catenin signaling and subsequently increasing BMP2 expression. In vivo periosteal boneformation assay by local injection of osthole indicated osthole promoted new bone formation; in addition, comparison of bone microarchitecture, histomorphometric parameters, and biomechanical properties in OVX rat treated with or without osthole revealed that treatment with osthole effectively prevented bone loss in OVX rats [37].

2.3. Immunomodulation and Anti-Inflammatory Activity. In late 1990s, a German research group first reported osthole's selective inhibitory effect on 5-lipoxygenase (5-LO) and cyclooxygenase- (COX-) $1[38,39]$. Both enzymes are critical in the process of inflammation, and inhibition of COX is shown to relieve pain and inflammatory symptoms [40], whereas 5LO is considered a target for pharmaceutical intervention in various kinds of diseases aside from inflammatory diseases, like cardiovascular diseases, cancer, and osteoporosis [41]. In cell culture, osthole suppressed the immune response of lipopolysaccharide-stimulated macrophages by decreasing reactive oxygen species (ROS) release and inhibiting enzymes including inducible nitric oxide synthase (iNOS), mitogenactivated protein kinases (MAPK), and COX-2 [42, 43]. Osthole also suppressed interleukin- (IL-) 4 and tumor necrosis factor- (TNF-) $\alpha$ induced eotaxin expression in bronchial epithelial BEAS-2B cells [44] and inhibited hypertrophic scar fibroblasts through inducing apoptosis and downregulating TGF- $\beta$ expression [45]. Similar anti-inflammatory activates of osthole have also been found in rat peritoneal cells and human peripheral blood mononuclear cells [46]. Meanwhile, anti-inflammatory effect of osthole was also confirmed in animal models. Results from carrageenan-induced hind paw edema in rats suggested that osthole suppressed production of prostaglandin (PG), nitric oxide (NO), and malondialdehyde (MDA), as well as downregulated activity of NOS, which was likely to associate with the elevation of cyclic adenosine monophosphate (cAMP) and cyclic adenosine monophosphate (cGMP) levels [47]. Osthole also inhibited the expression of COX-2 and NOS in dorsal root ganglion and relieved mechanical allodynia in rat model of sciatica induced by lumbar disc herniation [48]. The chemical was also reported to have antiallergic effect in passive cutaneous anaphylaxis (PCA), 2, 4-dinitrofluorobenzene (DNFB), and picryl 


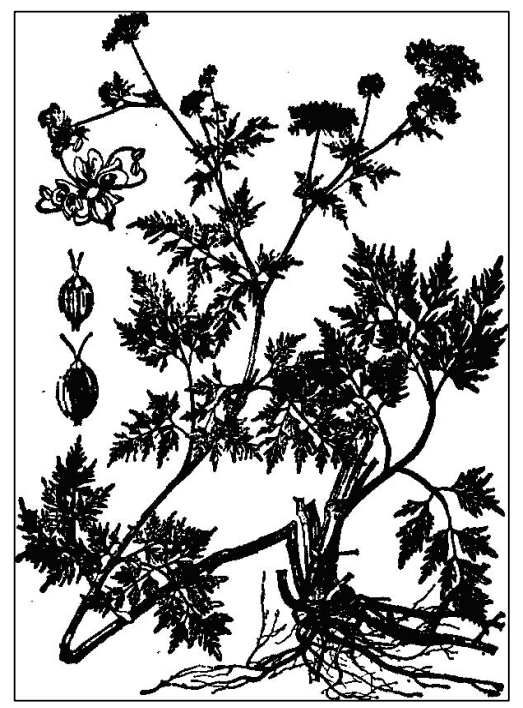

(a)

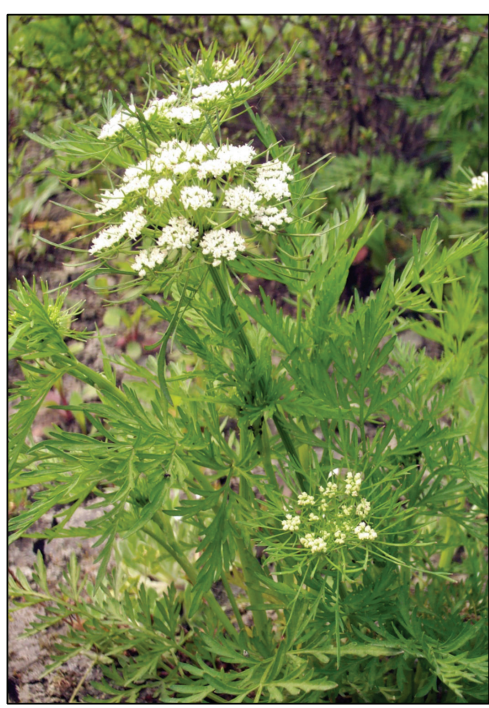

(b)

FIgURE 2: Illustration of the whole plant Cnidium monnieri with the fruit structure (a) and photo of the upper ground parts of the herb (b) (modified from http://www.google.com/).

chloride- (PC-) induced contact dermatitis in experimental animals [49].

2.4. Anticancer Effect. Accumulating experimental evidences have shown that osthole exhibited antiproliferative properties and induced apoptosis in various kinds of tumor cells $[2,50]$, including leukemia HL-60 [51], L1210 [52]; prostatic cancer cell LNCaP, PC3, and DU145 [52]; cervical cancer cell Hela [53]; ovarian cancer cell SKOV3 [54]; lung cancer cell A549 [55]; SK-LU-1 [56]; epidermal cancer cell KB [56]; breast cancer cell MCF-7 [54, 56, 57], MDA-MB-231 [54, 57], and 4T1 [57]; and hepatocellular carcinoma (HCC) HepG2 [56], SMMC-7721, and Hepal-6 [58]. The antitumor activities of osthole have also been supported with in vivo results showing prolonged survival days of P-388 D1 tumor-bearing CDF mice [53] and suppressed tumor growth in HCC tumor models established by injection of SMMC-7721 or Hepal-6 cells [58]. It is noteworthy that osthole successfully inhibited the migration and invasion of metastatic cancer cells. Yang et al. firstly reported that osthole inhibited migration of MCF-7 cells and invasion of MDA-MB-231 cells and suggested that suppression of matrix metalloproteinases (MMP) enzyme activities might be the possible mechanism [57]. Prevention of cell migration and invasion was also reported in human lung adenocarcinoma CL1-5, H1299, and A549 [59]. Additionally, combination of osthole and other nature products showed synergetic effect on inhibition of tumor cell proliferation and invasion [60-62].

The molecular mechanism of anticancer effect of osthole still remains unclear. It is highly likely to be combinatory effects on carcinogenesis and tumor progression. Osthole has been suggested to modulate PI3K/Akt signaling pathway leading to G2/M arrest and apoptosis in lung cancer A549 cells [55]. It downregulates FASN, which is highly expressed in many solid tumors, in HER2-overexpressing breast cancer cells through inhibiting the c-Met/Akt/mTOR pathway [54, 63]. Osthole also normalized plasma alanine aminotransferase (ALT) which has been proved to be a strategy for preventing the development of HCC [64]. Moreover, osthole inhibited cancer cells invasion and transition through suppression of MMP-2 and MMP-9 which were induced by a serial of inflammatory factors $[57,59,61,62]$. Besides, osthole was demonstrated as promising therapeutic agent for cancer treatment due to histone deacetylase inhibition $[65,66]$.

2.5. Hepatoprotective Effect and Benefits on Metabolic Diseases. Liver is regarded as one of the vital organs that functions as a center for metabolism of nutrients and excretion of wastes. Osthole exerts protective effects against hepatitis. It suppressed the secretion of hepatitis B virus (HBV) in cell culture [67] and prevented hepatitis in mice induced by concanavalin A or anti-Fas antibody [68-70]. Osthole also exhibited therapeutic effect on both hyperlipidemic [71-77] and alcoholic fatty liver animals [71, 75, 78, 79]. Mechanism studies revealed that osthole modulated expression of multiple lipogenic genes [77, 80], increased adiponectin release, and hence improved insulin resistance [76] via activation of $\mathrm{PPAR} \alpha / \gamma$ pathway. In addition, antifibrotic activity of osthole on HSC-T6 hepatic stellate cell lines was also reported [81].

Osthole is not only beneficial to liver but also beneficial to endocrine system and metabolism of the whole body. Screening for allosteric modulators of melanocortin- 4 receptor, a target for obesity and cachexia therapy, reported osthole and other two FC coumarins as potential modulators [82]. Osthole is regarded as a potential antidiabetic agent as well. In vitro and in vivo experiments demonstrated that osthole alleviated hyperglycemia by activating $\operatorname{PPAR} \alpha / \gamma$, AMP-activated protein kinase (AMPK), and downstream acetyl CoA carboxylase $[83,84]$. In addition, the Yang tonifying effect of osthole has been explored in modern experimental way. Oral 
administration of osthole significantly increased androgen, gonadotropin production, and NOS activity in immature castrate male rats [85]. Administration of osthole and FC coumarin extract improved immunological function in kidney yang deficiency animal models induced by hydrocortisone acetate [86], via elevated function of pituitary-thyroid [87], and pituitary-adrenocortex axis [88].

2.6. Vasorelaxant Properties and Cardiovascular Benefits. Osthole exhibits protective effect on heart and circulatory system. Abnormal vascular smooth muscle cell proliferation is a major component of vascular disease including atherosclerosis, vein graft occlusion, and restenosis after angioplasty, whereas osthole treatment selectively inhibits the proliferation of those vascular smooth muscle cells [89]. Osthole showed vasorelaxant properties due to its $\mathrm{Ca}^{2+}$-channel antagonistic effect and upregulation of cGMP level in vascular smooth muscle [90-92]. Osthole was also proposed to prevent isoprenaline-induced fibrosis through activating of $\operatorname{PPAR} \alpha / \gamma$ and subsequent suppression of NF- $\kappa \mathrm{B}$ production in myocardial tissues [93]. Additionally, accelerative effect on $\beta$-oxidation of hepatic fatty acids in hypertensive rats suggested it might be useful for prevention of atherosclerosis [80]. Osthole suppresses platelet aggregation via inhibition of thromboxane formation and phosphoinositides breakdown, thus making it a prospective antithrombotic agent $[94,95]$. Osthole exerts relaxant effect not only on blood vessels, but also on other tissues such as isolated rodent ileum and taeniae coli [96]; trachea [97]; and corpus cavernosum, which partially explain long history of using FC as a herbal medicine to improve male sexual dysfunction $[98,99]$.

2.7. Antimicrobial and Antiparasitic Effect. Osthole exerts antifungal properties on numbers of fungi species. Experimental evidences showed that osthole inhibited hypha growth of Fusarium graminearum, a parasite found on common weeds and cereal crops, through glucose starvation [100], and controlled powdery mildew caused by Sphaerotheca fuliginea via inhibiting spore germination and mycelia growth [101]. Osthole derivatives exhibited curative effect on pepper blight caused by Phytophthora capsici [102]. Other antibacterial activities on both gram positive and gram negative bacteria were also reported $[103,104]$. Osthole was also found to exhibit antiviral activity not only on HBV, but also on HIV1 by inhibiting Rev-export, which is critical in HIV-1 entails replication [105]. In addition, anthelmintic activity of osthole was also noted in goldfish against Dactylogyrus intermedius $[106,107]$.

\section{Pharmacokinetics and Metabolism of Osthole}

Pharmacokinetics of osthole in rat plasma after oral or intravenous administration was studied using HPLC method, yielding concentration/time curve with rapid distribution followed by a slower elimination phase [108-111]. Intestinal absorption of osthole was studied with HPLC in rat single pass intestine perfusion (SPIP) model, where results showed osthole absorption was a passive diffusion process in whole intestinal sections [112]. Osthole metabolism after oral administration was studied in male SD rats and 10 phase I and 3 phase II metabolites were isolated and identified from urine. The major phase I metabolic reactions were hydroxylation, demethylation, and hydrogenation, while glucuronidation contributed to phase II metabolism [113]. Absorption and metabolism of osthole were also investigated in human colorectal Caco- 2 cell model. Osthole demonstrated high absorptive permeability and accumulation in Caco-2 cells; major phase I metabolites were desmethyl-osthol and its multiple isomers $[114,115]$.

\section{Discussion}

4.1. Composite Bioactivities of Osthole on Body System. Osthole exerts a broad spectrum of biological and pharmacological activities. While effects of osthole are categorized under different biological activities in this paper, a lot of connections can actually be found among them (Figure 3). Osthole exhibits immunomodulatory and anti-inflammatory properties, by regulating the expression of a series of key factors, including TNF- $\alpha$, NF- $\kappa \mathrm{B}, \mathrm{TGF}-\beta, \mathrm{COX}, \mathrm{NO}, \mathrm{ERK}$, and JNK, involved in the process of immune response and other metabolic and biological processes. For instance, NF- $\kappa$ B plays important role in modulating immunological response, and disturbance of NF- $\kappa \mathrm{B}$ expression has been linked to some autoimmune diseases, cancer, and many other diseases. Likewise, TGF- $\beta$ is a cytokine involving in several key pathways which are related to the development of numerous diseases. Modulation by osthole on those critical factors probably contributes to its various benefits on systemic level. Principally, in various tissues and organs, the anti-inflammatory and antioxidative activities of osthole induce and magnify its anticancer properties and protective effects on other systems. Similarly, osthole showed antifibrotic effect in both hepatic and myocardial tissues, which contribute to the protective effect on liver and cardiovascular system. Osthole has also been suggested as a natural activator of defective DeltaF508cystic fibrosis transmembrane conductance regulator (CFTR) chloride channel gating and thus may be a lead compound for cystic fibrosis therapies [116, 117]. In addition, liver plays a critical role in metabolism including catabolism, storage, and anabolism. Hence, the numerous benefits on liver certainly contribute to better metabolic system of human body. Moreover, the positive influence of osthole to male sexual dysfunction has been found related to vasorelaxant activity which was also reported in other tissues such as ileum and taeniae coli and thoracic aorta.

4.2. $c A M P$ and $c G M P$ Level. Accumulating evidence in studies for biological activities of osthole revealed that osthole exerts a nonspecific elevation of intracellular and tissue cAMP and cGMP, which is likely involved in the underlying mechanism of some bioactivities of osthole. cAMP and cGMP, derived from ATP and GTP, respectively, are second messenger prominent in many biological processes. cAMP mainly works by activating protein kinase A (PKA), as well as 


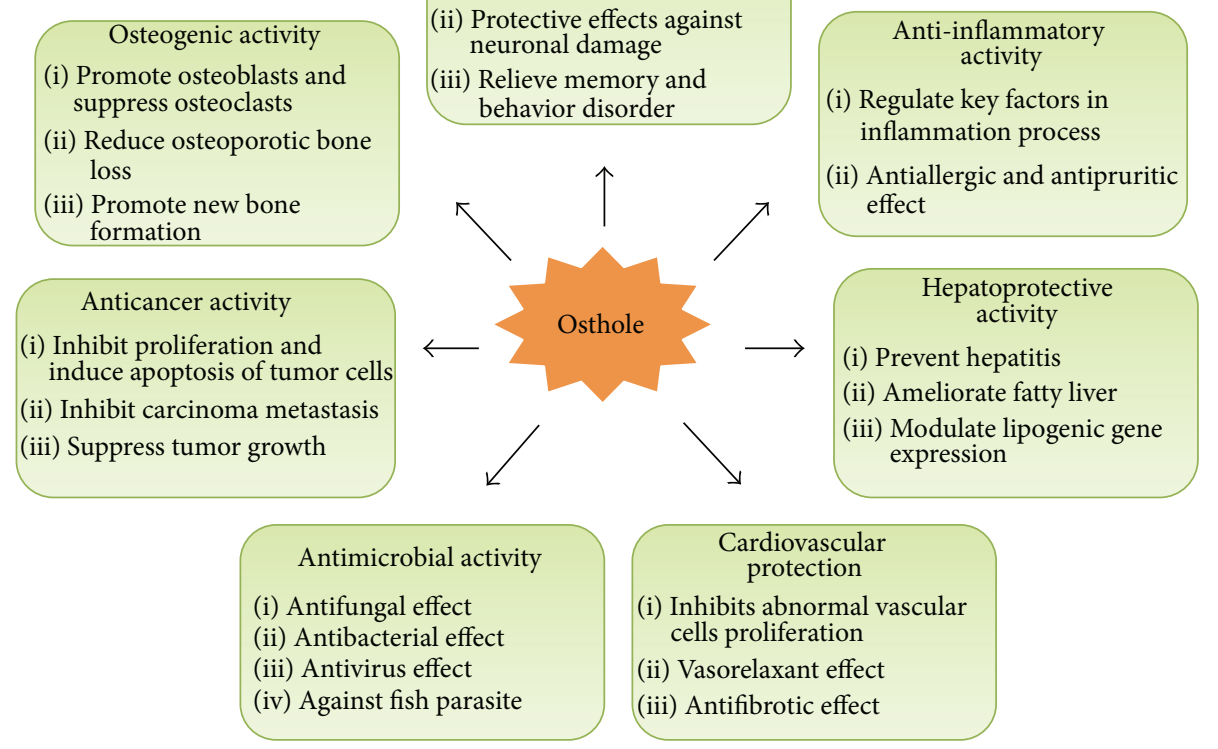

FIGURE 3: Multiple systemic pharmacological and beneficial effects and related experimental results.

directly affecting ion channels and growth hormone. cGMP is also a regulator of ion channels related to cell cycle arrest, apoptosis, and smooth muscle tissue relaxing as well. Osthole increases cAMP and cGMP level by inhibiting cAMP and cGMP phosphodiesterases (PDEs) which hydrolyze cAMP and CGMP by degradation of the phosphodiester bond $[95,97]$. The inhibitory effect on vascular smooth muscle cell was found to associate with osthole-induced elevation of cAMP and cGMP level [89], whereas osthole-facilitated glutamate release in hippocampal synaptosomes was associated with activation of cGMP/PKG-dependent pathway [10]. Osthole-mediated suppression of inflammatory factors in carrageenan-induced model was noted to attribute to cGMP elevation [47]. Moreover, researchers suggested that vasorelaxant property of osthole was linked to increased cAMP and cGMP levels caused by osthole treatment [92, 97, 99] (Figure 4).

4.3. Ion Channel Regulator. Osthole has been found to influence membrane potential and some types of ion channels in various cells and tissues, including sodium channel, acidsensing ion channel, chloride channel of CFTR, and especially calcium channel. Effect of osthole on these ion channels is closely related to bioactivities of osthole as vasorelaxant, immunomodulatory, antifibrotic effects, and, in particular, its neuronal and neuroendocrine functions including neuroprotective, anticonvulsant, and pain relieving properties. On the other hand, calcium concentration regulates the osteoprogenitors behavior which play important roles in both bone homeostasis and regeneration $[117,118]$, thereby making calcium channel a prospective direction to study the mechanism of osteogenic effect of osthole. cAMP and cGMP have been well documented as important regulators of L-type $\mathrm{Ca}^{2+}$ channel and some other ion channels [119-121]. Therefore, effect of osthole on ion channels is at least partially induced by modulation of cAMP and cGMP level (Figure 4).

4.4. 5-Lipoxygenase Inhibitor. 5-lipoxygenase (5-LO) is a rate-limiting dioxygenase in the process of leukotrienes (LTs) biosynthesis from the precursor arachidonic acid. As LTs are key mediators in immune and inflammatory responses in pathophysiology of numbers of respiratory and cardiovascular diseases, 5-LO is regarded as a target in developing therapy of related diseases and 5-LO inhibitors are being developed as a treatment approach. Osthole has been reported to be a 5-LO inhibitor in previous studies. Meanwhile, researchers proposed that signaling through $\mathrm{CAMP} / \mathrm{PKA}$ results in phosphorylation and cytoplasmic sequestration of 5-LO and inhibition of LTs synthesis. It has been found that many cAMP-elevating agents such as isoproterenol, prostaglandin $\mathrm{E}$, and prostaglandins attenuate 5-LO translocation and LTs biosynthesis [122-124]. Therefore, inhibitory effect of osthole on 5-LO may also be associated with osthole-mediated cAMP elevation.

\section{Conclusion}

Plenty of experimental results demonstrated that osthole exhibits a variety of pharmacological benefits including neuroprotection, osteogenesis, immunomodulation, and cancercombating properties, making it a potential multitarget complementary medicine and functional food. The mechanisms underlying these properties have not been fully understood, yet the regulatory effect of osthole on cAMP and cGMP level and some ion channels can be seen as contributing to several of those properties. Further studies are needed to enrich 


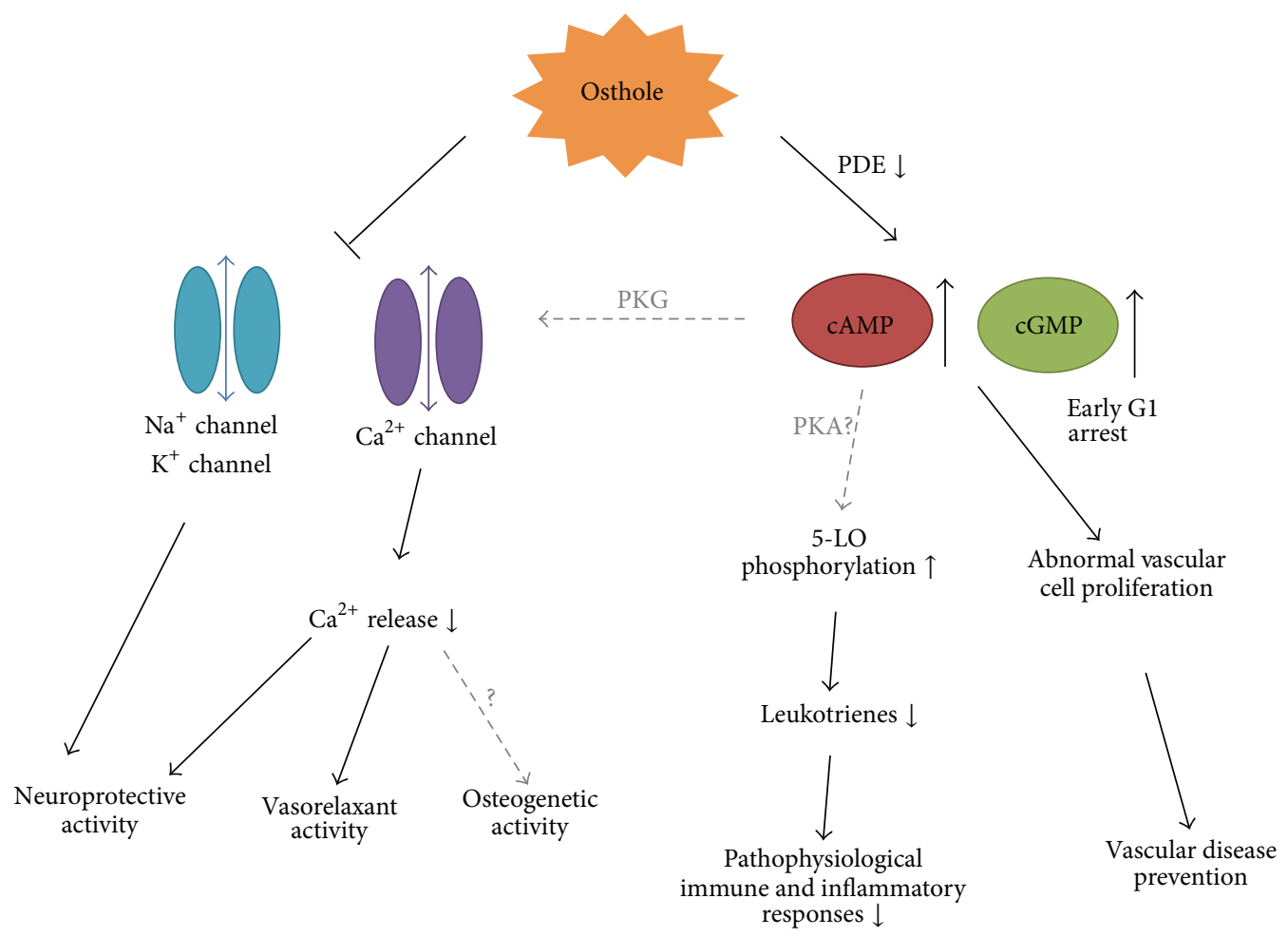

FIGURE 4: Possible interrelation between effect of osthole on intracellular ion channels, cyclic adenosine monophosphate (cAMP), and cyclic guanosine monophosphate (cGMP) levels with some of its pharmacological activities. (Hypotheses unconfirmed in studies of osthole are indicated with dashed line.)

the knowledge of the pharmacological effects and address the safety issues of osthole in order to develop this natural product and its derivatives as an agent for disease prevention and therapeutics in human.

\section{Conflict of Interests}

The authors declare that there is no conflict of interests regarding the publication of this paper.

\section{Acknowledgments}

This project is supported by General Research Fund, Hong Kong Research Grant Council (ref. no. 461113) and Research Committee Funding (Direct Grants) (ref. nos. 4053024 and 2030445).

\section{References}

[1] L. You, S. Feng, R. An, and X. Wang, "Osthole: a promising lead compound for drug discovery from a traditional Chinese medicine (TCM)," Natural Product Communications, vol. 4, no. 2, pp. 297-302, 2009.

[2] Z.-W. Zhou and P.-X. Liu, "Progress in study of chemical constituents and anti-tumor activities of Cnidium monnieri," Zhongguo Zhongyao Zazhi, vol. 30, no. 17, pp. 1309-1313, 2005.

[3] J. R. S. Hoult and M. Payá, "Pharmacological and biochemical actions of simple coumarins: natural products with therapeutic potential," General Pharmacology, vol. 27, no. 4, pp. 713-722, 1996.

[4] R. Wang, J. Kong, D. Wang, L. L.-M. Lien, and E. J.-C. Lien, "A survey of Chinese herbal ingredients with liver protection activities," Chinese Medicine, vol. 2, article 5, 2007.

[5] S.-N. Wu, Y.-K. Lo, C.-C. Chen, H.-F. Li, and H.-T. Chiang, "Inhibitory effect of the plant-extract osthole on L-type calcium current in NG108-15 neuronal cells," Biochemical Pharmacology, vol. 63, no. 2, pp. 199-206, 2002.

[6] Y.-M. Leung, Y.-H. Kuo, C.-C. Chao et al., "Osthol is a usedependent blocker of voltage-gated $\mathrm{Na}^{+}$channels in mouse neuroblastoma N2A cells," Planta Medica, vol. 76, no. 1, pp. 3440, 2010

[7] T. Ojala, P. Vuorela, H. Vuorela, and K. Törnquist, "The coumarin osthol attenuates the binding of thyrotropin-releasing hormone in rat pituitary GH4Cl cells," Planta Medica, vol. 67, no. 3, pp. 236-239, 2001.

[8] S.-J. Wang, T.-Y. Lin, C.-W. Lu, and W.-J. Huang, "Osthole and imperatorin, the active constituents of Cnidium monnieri (L.) Cusson, facilitate glutamate release from rat hippocampal nerve terminals," Neurochemistry International, vol. 53, no. 6-8, pp. 416-423, 2008.

[9] T.-Y. Lin, C.-W. Lu, W.-J. Huang, and S.-J. Wang, "Osthole or imperatorin-mediated facilitation of glutamate release is associated with a synaptic vesicle mobilization in rat hippocampal glutamatergic nerve endings," Synapse, vol. 64, no. 5, pp. 390396, 2010.

[10] T. Y. Lin, C. W. Lu, W.-J. Huang, and S.-J. Wang, "Involvement of the cGMP pathway in the osthole-facilitated glutamate release 
in rat hippocampal nerve endings," Synapse, vol. 66, no. 3, pp. 232-239, 2012.

[11] Q.-L. He, Y. Chen, J. Qin et al., "Osthole, a herbal compound, alleviates nucleus pulposus-evoked nociceptive responses through the suppression of overexpression of acid-sensing ion channel 3 (ASIC3) in rat dorsal root ganglion," Medical Science Monitor, vol. 18, no. 6, pp. BR229-BR236, 2012.

[12] J. J. Luszczki, E. Wojda, M. Andres-Mach et al., "Anticonvulsant and acute neurotoxic effects of imperatorin, osthole and valproate in the maximal electroshock seizure and chimney tests in mice: a comparative study," Epilepsy Research, vol. 85, no. 2-3, pp. 293-299, 2009.

[13] J. J. Luszczki, M. Andres-Mach, W. Cisowski, I. Mazol, K. Glowniak, and S. J. Czuczwar, "Osthole suppresses seizures in the mouse maximal electroshock seizure model," European Journal of Pharmacology, vol. 607, no. 1-3, pp. 107-109, 2009.

[14] J. Zaugg, E. Eickmeier, D. C. Rueda, S. Hering, and M. Hamburger, "HPLC-based activity profiling of Angelica pubescens roots for new positive $\mathrm{GABA}_{A}$ receptor modulators in Xenopus oocytes," Fitoterapia, vol. 82, no. 3, pp. 434-440, 2011.

[15] J. Singhuber, I. Baburin, G. F. Ecker, B. Kopp, and S. Hering, "Insights into structure-activity relationship of $\mathrm{GABA}_{A}$ receptor modulating coumarins and furanocoumarins," European Journal of Pharmacology, vol. 668, no. 1-2, pp. 57-64, 2011.

[16] W.-B. Liu, J. Zhou, Y. Qu et al., "Neuroprotective effect of osthole on $\mathrm{MPP}^{+}$-induced cytotoxicity in PC12 cells via inhibition of mitochondrial dysfunction and ROS production," Neurochemistry International, vol. 57, no. 3, pp. 206-215, 2010.

[17] H.-J. Ji, J.-F. Hu, Y.-H. Wang, X.-Y. Chen, R. Zhou, and N.H. Chen, "Osthole improves chronic cerebral hypoperfusion induced cognitive deficits and neuronal damage in hippocampus," European Journal of Pharmacology, vol. 636, no. 1-3, pp. 96-101, 2010.

[18] X. Chao, J. Zhou, T. Chen et al., "Neuroprotective effect of osthole against acute ischemic stroke on middle cerebral ischemia occlusion in rats," Brain Research, vol. 1363, pp. 206-211, 2010.

[19] X. Mao, W. Yin, M. Liu et al., "Osthole, a natural coumarin, improves neurobehavioral functions and reduces infarct volume and matrix metalloproteinase- 9 activity after transient focal cerebral ischemia in rats," Brain Research, vol. 1385, pp. 275-280, 2011.

[20] T. Chen, W. Liu, X. Chao et al., "Neuroprotective effect of osthole against oxygen and glucose deprivation in rat cortical neurons: involvement of mitogen-activated protein kinase pathway," Neuroscience, vol. 183, pp. 203-211, 2011.

[21] L. Wu, S.-Y. Cheng, Q. Wang, and Y.-B. Chen, "Advances in study on the pharmacological effects of active components of Chinese herbs on Alzheimer's disease," Zhongguo Zhongyao Zazhi, vol. 29, no. 5, pp. 388-389, 2004.

[22] L.-X. Shen, L.-Q. Jin, D.-S. Zhang, and G.-P. Xue, "Effect of osthol on memory impairment of mice in $\mathrm{AlCl} 3$-induced acute senile model," Yao Xue Xue Bao, vol. 37, no. 3, pp. 178-180, 2002.

[23] C.-R. Wu, L.-W. Lin, C.-L. Hsieh, W.-H. Wang, Y.-T. Lin, and M.-T. Hsieh, "Petroleum ether extract of Cnidium monnieri ameliorated scopolamine-induced amnesia through adrenal gland-mediated mechanism in male rats," Journal of Ethnopharmacology, vol. 117, no. 3, pp. 403-407, 2008.

[24] Y. He, S. Qu, J. Wang et al., "Neuroprotective effects of osthole pretreatment against traumatic brain injury in rats," Brain Research, vol. 1433, pp. 127-136, 2012.

[25] M.-T. Hsieh, C.-L. Hsieh, W.-H. Wang, C.-S. Chen, C.-J. Lin, and C.-R. Wu, "Osthole improves aspects of spatial performance in ovariectomized rats," American Journal of Chinese Medicine, vol. 32, no. 1, pp. 11-20, 2004.

[26] X. Chen, R. Pi, Y. Zou et al., "Attenuation of experimental autoimmune encephalomyelitis in C57 BL/6 mice by osthole, a natural coumarin," European Journal of Pharmacology, vol. 629, no. 1-3, pp. 40-46, 2010.

[27] W. Zhang, D. Ma, Q. Zhao, and T. Ishida, "The effect of the major components of Fructus Cnidii on osteoblasts in vitro," JAMS Journal of Acupuncture and Meridian Studies, vol. 3, no. 1, pp. 32-37, 2010.

[28] L. G. Ming, B. F. Ge, K. M. Chen et al., "Effect of Osthol on the proliferation and differentiate of osteoblasts in vitro," Zhongguo Gu Shang, vol. 23, no. 9, pp. 688-691, 2010.

[29] L.-P. Qin, Q.-Y. Zhang, Y.-P. Tian, H.-C. Zheng, M. Huang, and B.-K. Huang, "Total coumarins from fruits of Cnidium monnieri inhibit formation and differentiation of multinucleated osteoclasts of rats," Acta Pharmacologica Sinica, vol. 24, no. 2, pp. 181186, 2003.

[30] L.-G. Ming, J. Zhou, G.-Z. Cheng, H.-P. Ma, and K.-M. Chen, "Osthol, a coumarin isolated from common cnidium fruit, enhances the differentiation and maturation of osteoblasts in vitro," Pharmacology, vol. 88, no. 1-2, pp. 33-43, 2011.

[31] Q. Zhang, L. Qin, W. He et al., "Coumarins from Cnidium monnieri and their antiosteoporotic activity," Planta Medica, vol. 73, no. 1, pp. 13-19, 2007.

[32] L.-G. Ming, M.-G. Wang, K.-M. Chen, J. Zhou, G.-Q. Han, and R.-Q. Zhu, "Effect of osthol on apoptosis and bone resorption of osteoclasts cultured in vitro," Yaoxue Xuebao, vol. 47, no. 2, pp. 174-179, 2012.

[33] Q. N. Li, N. C. Liang, T. Wu et al., "Effects of total coumarins of Fructus cnidii on skeleton of ovariectomized rats," Zhongguo Yao Li Xue Bao, vol. 15, no. 6, pp. 528-532, 1994.

[34] C. Y. Li, T. Wu, Q. N. Li et al., "Quantitative study on the effect of osthole on proximal tibiae in ovariectomized(OVX) rats," Yaoxue Xuebao, vol. 31, no. 5, pp. 327-332, 1996 (Chinese).

[35] J.-M. Liao, Q.-A. Zhu, H.-J. Lu, Q.-N. Li, T. Wu, and L.F. Huang, "Effects of total coumarins of Cnidium monnieri on bone density and biomechanics of glucocorticoids-induced osteoporosis in rats," Acta Pharmacologica Sinica, vol. 18, no. 6, pp. 519-521, 1997.

[36] X. L. Xiao, I. Hara, and T. Matsumiya, "Effects of osthole on postmenopausal osteoporosis using ovariectomized rats; comparison to the effects of estradiol," Biological \& Pharmaceutical Bulletin, vol. 25, no. 6, pp. 738-742, 2002.

[37] D.-Z. Tang, W. Hou, Q. Zhou et al., "Osthole stimulates osteoblast differentiation and bone formation by activation of betacatenin-BMP signaling," Journal of Bone and Mineral Research, vol. 25, no. 6, pp. 1234-1245, 2010.

[38] J. H. Liu, S. Zschocke, E. Reininger, and R. Bauer, "Inhibitory effects of Angelica pubescens f. biserrata on 5-lipoxygenase and cyclooxygenase," Planta Medica, vol. 64, no. 6, pp. 525-529, 1998.

[39] M. Resch, A. Steigel, Z.-L. Chen, and R. Bauer, "5-lipoxygenase and cyclooxygenase-1 inhibitory active compounds from Atractylodes lancea," Journal of Natural Products, vol. 61, no. 3, pp. 347-350, 1998.

[40] K. Seibert, Y. Zhang, K. Leahy et al., "Pharmacological and biochemical demonstration of the role of cyclooxygenase 2 in inflammation and pain," Proceedings of the National Academy of Sciences of the United States of America, vol. 91, no. 25, pp. 12013-12017, 1994. 
[41] C. Pergola and O. Werz, "5-Lipoxygenase inhibitors: a review of recent developments and patents," Expert Opinion on Therapeutic Patents, vol. 20, no. 3, pp. 355-375, 2010.

[42] T. Nakamura, N. Kodama, Y. Arai et al., "Inhibitory effect of oxycoumarins isolated from the Thai medicinal plant Clausena guillauminii on the inflammation mediators, iNOS, TNF-alpha, and COX-2 expression in mouse macrophage RAW 264.7," Journal of Natural Medicines, vol. 63, no. 1, pp. 21-27, 2009.

[43] P.-C. Liao, S.-C. Chien, C.-L. Ho et al., "Osthole regulates inflammatory mediator expression through modulating NF$\mathrm{KB}$, mitogen-activated protein kinases, protein kinase $\mathrm{C}$, and reactive oxygen species," Journal of Agricultural and Food Chemistry, vol. 58, no. 19, pp. 10445-10451, 2010.

[44] P.-R. Chiu, W.-T. Lee, Y.-T. Chu, M.-S. Lee, Y.-J. Jong, and C.H. Hung, "Effect of the Chinese herb extract osthol on IL-4induced eotaxin expression in BEAS-2B cells," Pediatrics and Neonatology, vol. 49, no. 4, pp. 135-140, 2008.

[45] X.-H. Hou, B. Cao, H.-Q. Liu, Y.-Z. Wang, S.-F. Bai, and H. Chen, "Effects of osthole on apoptosis and TGF- $\beta 1$ of hypertrophic scar fibroblasts," Journal of Asian Natural Products Research, vol. 11, no. 7, pp. 663-669, 2009.

[46] M. Zimecki, J. Artym, W. Cisowski, I. Mazol, M. Włodarczyk, and M. Gleńsk, "Immunomodulatory and anti-inflammatory activity of selected osthole derivatives," Zeitschrift fur Naturforschung-Section C, vol. 64, no. 5-6, pp. 361-368, 2009.

[47] J. Liu, W. Zhang, L. Zhou, X. Wang, and Q. Lian, "Anti-inflammatory effect and mechanism of osthole in rats," Journal of Chinese Medicinal Materials, vol. 28, no. 11, pp. 1002-1006, 2005.

[48] M. Wei, J.-J. Zhang, Q.-L. He et al., "Effects and mechanisms of osthole on sciatica induced by lumber disc herniation," Zhong Yao Cai, vol. 34, no. 5, pp. 746-750, 2011.

[49] H. Matsuda, N. Tomohiro, Y. Ido, and M. Kubo, "Anti-allergic effects of cnidii monnieri fructus (dried fruits of Cnidium monnieri) and its major component, osthol," Biological \& Pharmaceutical Bulletin, vol. 25, no. 6, pp. 809-812, 2002.

[50] S. Kawaii, Y. Tomono, K. Ogawa et al., "Antiproliferative effect of isopentenylated coumarins on several cancer cell lines," Anticancer Research, vol. 21, no. 3, pp. 1905-1911, 2001.

[51] L.-L. Yang, M.-C. Wang, L.-G. Chen, and C.-C. Wang, "Cytotoxic activity of coumarins from the fruits of Cnidium monnieri on leukemia cell lines," Planta Medica, vol. 69, no. 12, pp. 10911095, 2003.

[52] C. Riviere, L. Goossens, N. Pommery, C. Fourneau, A. Delelis, and J. P. Henichart, "Antiproliferative effects of isopentenylated coumarins isolated from Phellolophium madagascariense Baker," Natural Product Research, vol. 20, no. 10, pp. 909-916, 2006.

[53] S.-Y. Chou, C.-S. Hsu, K.-T. Wang, M.-C. Wang, and C.-C. Wang, "Antitumor effects of osthol from Cnidium monnieri: an in vitro and in vivo study," Phytotherapy Research, vol. 21, no. 3, pp. 226-230, 2007.

[54] V. C.-H. Lin, C.-H. Chou, Y.-C. Lin et al., "Osthole suppresses fatty acid synthase expression in HER2-overexpressing breast cancer cells through modulating Akt/mTOR pathway," Journal of Agricultural and Food Chemistry, vol. 58, no. 8, pp. 47864793, 2010.

[55] X. Xu, Y. Zhang, D. Qu, T. Jiang, and S. Li, "Osthole induces G2/M arrest and apoptosis in lung cancer A549 cells by modulating PI3K/Akt pathway," Journal of Experimental \& Clinical Cancer Research, vol. 30, no. 1, article 33, 2011.
[56] P. H. Dien, N. T. Nhan, H. T. Le Thuy, and D. N. Quang, "Main constituents from the seeds of Vietnamese Cnidium monnieri and cytotoxic activity," Natural Product Research, vol. 26, no. 22, pp. 2107-2111, 2012.

[57] D. Yang, T. Gu, T. Wang, Q. Tang, and C. Ma, "Effects of osthole on migration and invasion in breast cancer cells," Bioscience, Biotechnology and Biochemistry, vol. 74, no. 7, pp. 1430-1434, 2010.

[58] L. Zhang, G. Jiang, F. Yao et al., "Growth inhibition and apoptosis induced by osthole, a natural coumarin, in Hepatocellular Carcinoma," PLoS ONE, vol. 7, no. 5, Article ID e37865, 2012.

[59] S.-J. Kao, J.-L. Su, C.-K. Chen et al., "Osthole inhibits the invasive ability of human lung adenocarcinoma cells via suppression of NF- $\kappa$ B-mediated matrix metalloproteinase- 9 expression," Toxicology and Applied Pharmacology, vol. 261, no. 1, pp. 105$115,2012$.

[60] X.-H. Han, Y.-Y. Ye, B.-F. Guo, and S. Liu, "Effects of platycodin $\mathrm{D}$ in combination with different active ingredients of Chinese herbs on proliferation and invasion of 4T1 and MDA-MB-231 breast cancer cell lines," Journal of Chinese Integrative Medicine, vol. 10, no. 1, pp. 67-75, 2012.

[61] B.-F. Guo, S. Liu, Y.-Y. Ye, and X.-H. Han, "Inhibitory effects of osthole, psoralen and aconitine on invasive activities of breast cancer MDA-MB-231BO cell line and the mechanisms," Journal of Chinese Integrative Medicine, vol. 9, no. 10, pp. 1110-1117, 2011.

[62] L. Sheng, C. Y. Wu, and X. F. Chen, "Inhibitory acting mechanism of psoralen-osthole on bone metastasis of breast canceran expatiation viewing from OPG/RANKL/RANK system," Zhongguo Zhong Xi Yi Jie He Za Zhi, vol. 31, no. 5, pp. 684-689, 2011.

[63] C.-M. Hung, D.-H. Kuo, C.-H. Chou, Y.-C. Su, C.-T. Ho, and T.D. Way, "Osthole suppresses hepatocyte growth factor (HGF)induced epithelial-mesenchymal transition via repression of the c-Met/Akt/mTOR pathway in human breast cancer cells," Journal of Agricultural and Food Chemistry, vol. 59, no. 17, pp. 9683-9690, 2011.

[64] T. Okamoto, T. Kobayashi, and S. Yoshida, "Chemical aspects of coumarin compounds for the prevention of hepatocellular carcinomas," Current Medicinal Chemistry: Anti-Cancer Agents, vol. 5, no. 1, pp. 47-51, 2005.

[65] W.-J. Huang, C.-C. Chen, S.-W. Chao et al., "Synthesis of nhydroxycinnamides capped with a naturally occurring moiety as inhibitors of histone deacetylase," ChemMedChem, vol. 5, no. 4, pp. 598-607, 2010.

[66] W.-J. Huang, C.-C. Chen, S.-W. Chao et al., "Synthesis and evaluation of aliphatic-chain hydroxamates capped with osthole derivatives as histone deacetylase inhibitors," European Journal of Medicinal Chemistry, vol. 46, no. 9, pp. 4042-4049, 2011.

[67] R.-L. Huang, C.-C. Chen, Y.-L. Huang et al., "Osthole increases glycosylation of hepatitis B surface antigen and suppresses the secretion of hepatitis B virus in vitro," Hepatology, vol. 24, no. 3, pp. 508-515, 1996.

[68] T. Okamoto, S. Yoshida, T. Kobayashi, and S. Okabe, "Inhibition of concanavalin A-induced mice hepatitis by coumarin derivatives," Japanese Journal of Pharmacology, vol. 85, no. 1, pp. 95-97, 2001.

[69] T. Okamoto, T. Kawasaki, and O. Hino, "Osthole prevents antiFas antibody-induced hepatitis in mice by affecting the caspase3-mediated apoptotic pathway," Biochemical Pharmacology, vol. 65, no. 4, pp. 677-681, 2003. 
[70] T. Okamoto, T. Kobayashi, and S. Yoshida, "Synthetic derivatives of osthole for the prevention of hepatitis," Medicinal Chemistry, vol. 3, no. 1, pp. 35-44, 2007.

[71] F. Song, M.-L. Xie, L.-J. Zhu, K.-P. Zhang, J. Xue, and Z.-L. Gu, "Experimental study of osthole on treatment of hyperlipidemic and alcoholic fatty liver in animals," World Journal of Gastroenterology, vol. 12, no. 27, pp. 4359-4363, 2006.

[72] Y. Zhang, M.-L. Xie, L.-J. Zhu, and Z.-L. Gu, "Therapeutic effect of osthole on hyperlipidemic fatty liver in rats," Acta Pharmacologica Sinica, vol. 28, no. 3, pp. 398-403, 2007.

[73] Y. Zhang, M. Xie, J. Xue, and Z. Gu, "Osthole improves fat milk-induced fatty liver in rats: modulation of hepatic PPARalpha/gamma-mediated lipogenic gene expression," Planta Medica, vol. 73, no. 8, pp. 718-724, 2007.

[74] Y. Zhang, M.-L. Xie, J. Xue, and Z.-L. Gu, "Osthole regulates enzyme protein expression of CYP7A1 and DGAT2 via activation of PPARalpha/gamma in fat milk-induced fatty liver rats," Journal of Asian Natural Products Research, vol. 10, no. 7-8, pp. 807-812, 2008.

[75] F. Sun, M.-L. Xie, J. Xue, and H.-B. Wang, "Osthol regulates hepatic PPAR $\alpha$-mediated lipogenic gene expression in alcoholic fatty liver murine," Phytomedicine, vol. 17, no. 8-9, pp. 669-673, 2010.

[76] Z. Qi, J. Xue, Y. Zhang, H. Wang, and M. Xie, "Osthole ameliorates insulin resistance by increment of adiponectin release in high-fat and high-sucrose-induced fatty liver rats," Planta Medica, vol. 77, no. 3, pp. 231-235, 2011.

[77] R. Du, J. Xue, H.-B. Wang, Y. Zhang, and M.-L. Xie, "Osthol ameliorates fat milk-induced fatty liver in mice by regulation of hepatic sterol regulatory element-binding protein-1c/2mediated target gene expression," European Journal of Pharmacology, vol. 666, no. 1-3, pp. 183-188, 2011.

[78] J. Zhang, J. Xue, H. Wang, Y. Zhang, and M. Xie, "Osthole improves alcohol-induced fatty liver in mice by reduction of hepatic oxidative stress," Phytotherapy Research, vol. 25, no. 5, pp. 638-643, 2011.

[79] F. Sun, M. L. Xie, L. J. Zhu, J. Xue, and Z. L. Gu, "Inhibitory effect of osthole on alcohol-induced fatty liver in mice," Digestive and Liver Disease, vol. 41, no. 2, pp. 127-133, 2009.

[80] H. Ogawa, N. Sasai, T. Kamisako, and K. Baba, "Effects of osthol on blood pressure and lipid metabolism in stroke-prone spontaneously hypertensive rats," Journal of Ethnopharmacology, vol. 112, no. 1, pp. 26-31, 2007.

[81] E. Shin, C. Lee, S. H. Sung, Y. C. Kim, B. Y. Hwang, and M. K. Lee, "Antifibrotic activity of coumarins from Cnidium monnieri fruits in HSC-T6 hepatic stellate cells," Journal of Natural Medicines, vol. 65, no. 2, pp. 370-374, 2011.

[82] J. Pantel, S. Y. Williams, D. Mi et al., "Development of a high throughput screen for allosteric modulators of melanocortin4 receptor signaling using a real time cAMP assay," European Journal of Pharmacology, vol. 660, no. 1, pp. 139-147, 2011.

[83] H.-J. Liang, F.-M. Suk, C.-K. Wang et al., "Osthole, a potential antidiabetic agent, alleviates hyperglycemia in $\mathrm{db} / \mathrm{db}$ mice," Chemico-Biological Interactions, vol. 181, no. 3, pp. 309-315, 2009.

[84] W.-H. Lee, R.-J. Lin, S.-Y. Lin, Y.-C. Chen, H.-M. Lin, and Y.-C. Liang, "Osthole enhances glucose uptake through activation of AMP-activated protein kinase in skeletal muscle cells," Journal of Agricultural and Food Chemistry, vol. 59, no. 24, pp. 1287412881, 2011.
[85] J. Yuan, J. Xie, A. Li, and F. Zhou, "Effects of osthol on androgen level and nitric oxide synthase activity in castrate rats," Zhong Yao Cai, vol. 27, no. 7, pp. 504-506, 2004.

[86] L. P. Qin, H. B. Wang, and J. Q. Zhang, "Effects of osthol and total-coumarins from Cnidium monnieri on immunological function in kidney yang deficiency mice," Zhongguo Zhong Xi Yi Jie He Za Zhi, vol. 15, no. 9, pp. 547-549, 1995.

[87] L. P. Qin, H. M. Zhang, and W. D. Zhang, "Effect of osthol and total coumarins of fructus cnidii on thyroid hormone and thyrotropic hormone in kidney-yang deficiency rats," Zhongguo Zhong Xi Yi Jie He Za Zhi, vol. 16, no. 9, pp. 552-553, 1996.

[88] L. P. Qin, J. Q. Zhang, and H. P. Shi, "Effects of coumarins from cnidium monnieri on the function of pituitary-adrenocortical axis in kidney yang deficiency rats," Zhongguo Zhong Xi Yi Jie He Za Zhi, vol. 17, no. 4, pp. 227-229, 1997 (Chinese).

[89] J.-H. Guh, S.-M. Yu, F.-N. Ko, T.-S. Wu, and C.-M. Teng, "Antiproliferative effect in rat vascular smooth muscle cells by osthole, isolated from Angelica pubescens," European Journal of Pharmacology, vol. 298, no. 2, pp. 191-197, 1996.

[90] L. Li, F.-E. Zhuang, L. Yang, C.-L. Zhang, G.-S. Zhao, and D.K. Zhao, "Effects of osthole on isolated guinea pig heart atria," Zhongguo Yao Li Xue Bao, vol. 16, no. 3, pp. 251-254, 1995.

[91] F. Fusi, G. Sgaragli, L. M. Ha, N. M. Cuong, and S. Saponara, "Mechanism of osthole inhibition of vascular $\mathrm{Ca}_{v} 1.2$ current," European Journal of Pharmacology, vol. 680, no. 1-3, pp. 22-27, 2012.

[92] F.-N. Ko, T.-S. Wu, M.-J. Liou, T.-F. Huang, and C.-M. Teng, "Vasorelaxation of rat thoracic aorta caused by osthole isolated from Angelica pubescens," European Journal of Pharmacology, vol. 219, no. 1, pp. 29-34, 1992.

[93] R. Chen, J. Xue, and M.-L. Xie, "Reduction of isoprenalineinduced myocardial TGF- $\beta 1$ expression and fibrosis in ostholetreated mice," Toxicology and Applied Pharmacology, vol. 256, no. 2, pp. 168-173, 2011.

[94] F.-N. Ko, T.-S. Wu, M.-J. Liou, T.-F. Huang, and C.-M. Teng, "Inhibition of platelet thromboxane formation and phosphoinositide breakdown by osthole from Angelica pubescens," Thrombosis and Haemostasis, vol. 62, no. 3, pp. 996-999, 1989.

[95] C.-M. Teng, F.-N. Ko, J.-P. Wang et al., "Antihaemostatic and antithrombotic effect of some antiplatelet agents isolated from Chinese herbs," The Journal of Pharmacy and Pharmacology, vol. 43, no. 9, pp. 667-669, 1991.

[96] L. Li, F. E. Zhuang, G. S. Zhao, and D. K. Zhao, "Effects of osthole on the isolated guinea-pig ileum and taeniae coli," Acta Pharmaceutica Sinica, vol. 28, no. 12, pp. 899-904, 1993.

[97] C.-M. Teng, C.-H. Lin, F.-N. Ko, T.-S. Wu, and T.-F. Huang, "The relaxant action of osthole isolated from Angelica pubescens in guinea-pig trachea," Naunyn-Schmiedeberg's Archives of Pharmacology, vol. 349, no. 2, pp. 202-208, 1994.

[98] J. Chen, W.-F. Chiou, C.-C. Chen, and C.-F. Chen, "Effect of the plant-extract osthole on the relaxation of rabbit corpus cavernosum tissue in vitro," The Journal of Urology, vol. 163, no. 6, pp. 1975-1980, 2000.

[99] W.-F. Chiou, Y.-L. Huang, C.-F. Chen, and C.-C. Chen, "Vasorelaxing effect of coumarins from Cnidium monnieri on rabbit corpus cavernosum," Planta Medica, vol. 67, no. 3, pp. 282-284, 2001.

[100] Z. Shi, S. Shen, W. Zhou, F. Wang, and Y. Fan, "Fusarium graminearum growth inhibition due to glucose starvation caused by osthol," International Journal of Molecular Sciences, vol. 9, no. 3, pp. 371-382, 2008. 
[101] C.-M. Wang, W. Zhou, C.-X. Li, H. Chen, Z.-Q. Shi, and Y.J. Fan, "Efficacy of osthol, a potent coumarin compound, in controlling powdery mildew caused by Sphaerotheca fuliginea," Journal of Asian Natural Products Research, vol. 11, no. 9, pp. 783-791, 2009.

[102] C.-M. Wang, W. Guan, S. Fang et al., "Antifungal activity of the osthol derivative JS-B against Phytophthora capsici," Journal of Asian Natural Products Research, vol. 12, no. 8, pp. 672-679, 2010.

[103] M. Figueroa, I. Rivero-Cruz, B. Rivero-Cruz, R. Bye, A. Navarrete, and R. Mata, "Constituents, biological activities and quality control parameters of the crude extract and essential oil from Arracacia tolucensis var. multifida," Journal of Ethnopharmacology, vol. 113, no. 1, pp. 125-131, 2007.

[104] S. Rosselli, A. Maggio, G. Bellone et al., "Antibacterial and anticoagulant activities of coumarins isolated from the flowers of Magydaris tomentosa," Planta Medica, vol. 73, no. 2, pp. 116120, 2007.

[105] S. Tamura, T. Fujitani, M. Kaneko, and N. Murakami, "Prenylcoumarin with Rev-export inhibitory activity from Cnidii Monnieris Fructus," Bioorganic \& Medicinal Chemistry Letters, vol. 20, no. 12, pp. 3717-3720, 2010.

[106] G. Wang, Z. Zhou, C. Cheng, J. Yao, and Z. Yang, "Osthol and isopimpinellin from Fructus cnidii for the control of Dactylogyrus intermedius in Carassius auratus," Veterinary Parasitology, vol. 158, no. 1-2, pp. 144-151, 2008.

[107] K.-Y. Wang, L. Yao, Y.-H. Du, J.-B. Xie, J.-L. Huang, and Z.-Q. Yin, "Anthelmintic activity of the crude extracts, fractions, and osthole from Radix angelicae pubescentis against Dactylogyrus intermedius in goldfish (Carassius auratus) in vivo," Parasitology Research, vol. 108, no. 1, pp. 195-200, 2011.

[108] T. H. Tsai, T. R. Tsai, C. C. Chen, and C. F. Chen, "Pharmacokinetics of osthole in rat plasma using high-performance liquid chromatography," Journal of Pharmaceutical and Biomedical Analysis, vol. 14, no. 6, pp. 749-753, 1996.

[109] Y. Li, F. Meng, Z. Xiong, H. Liu, and F. Li, "HPLC determination and pharmacokinetics of osthole in rat plasma after oral administration of fructus cnidii extract," Journal of Chromatographic Science, vol. 43, no. 8, pp. 426-429, 2005.

[110] J. Zhou, S. W. Wang, and X. L. Sun, "Determination of osthole in rat plasma by high-performance liquid chromatograph using cloud-point extraction," Analytica Chimica Acta, vol. 608, no. 2, pp. 158-164, 2008.

[111] J. Zhou, P. Zeng, Z. H. Cheng, J. Liu, F. Q. Wang, and R. J. Qian, "Application of hollow fiber liquid phase microextraction coupled with high-performance liquid chromatography for the study of the osthole pharmacokinetics in cerebral ischemia hypoperfusion rat plasma," Journal of Chromatography B: Analytical Technologies in the Biomedical and Life Sciences, vol. 879, no. 23, pp. 2304-2310, 2011.

[112] Y.-N. Wu and L.-B. Luan, "In situ rats single pass perfusion intestinal absorption of the effective components in Radix Angelicae Pubescentis," Yao Xue Xue Bao, vol. 43, no. 1, pp. 102107, 2008.

[113] X. Lv, C.-Y. Wang, J. Hou et al., "Isolation and identification of metabolites of osthole in rats," Xenobiotica, vol. 42, no. 11, pp. 1120-1127, 2012.

[114] X.-W. Yang, Q.-M. Guo, and Y. Wang, "Absorption and transport of 6 coumarins isolated from the roots of Angelica pubescens $\mathrm{f}$. biserrata in human Caco-2 cell monolayer model," Zhong Xi Yi Jie He Xue Bao, vol. 6, no. 4, pp. 392-398, 2008.
[115] Z. Yuan, H. Xu, K. Wang, Z. Zhao, and M. Hu, "Determination of osthol and its metabolites in a phase I reaction system and the Caco-2 cell model by HPLC-UV and LC-MS/MS," Journal of Pharmaceutical and Biomedical Analysis, vol. 49, no. 5, pp. 1226-1232, 2009.

[116] L.-N. Xu, W.-L. Na, X. Liu et al., "Identification of natural coumarin compounds that rescue defective $\Delta$ F508-CFTR chloride channel gating," Clinical and Experimental Pharmacology and Physiology, vol. 35, no. 8, pp. 878-883, 2008.

[117] H. Yang, L. N. Xu, Y. J. Sui et al., "Stimulation of airway and intestinal mucosal secretion by natural coumarin CFTR activators," Frontiers in Pharmacology, vol. 2, article 52, 2011.

[118] A. M. C. Barradas, H. A. M. Fernandes, N. Groen et al., "A calcium-induced signaling cascade leading to osteogenic differentiation of human bone marrow-derived mesenchymal stromal cells," Biomaterials, vol. 33, no. 11, pp. 3205-3215, 2012.

[119] C. L. Chik, Q.-Y. Liu, B. Li, E. Karpinski, and A. K. Ho, "cGMP Inhibits L-type $\mathrm{Ca}^{2+}$ channel currents through protein phosphorylation in rat pinealocytes," Journal of Neuroscience, vol. 15, no. 4, pp. 3104-3109, 1995.

[120] T. J. Kamp and J. W. Hell, "Regulation of cardiac L-type calcium channels by protein kinase A and protein kinase C," Circulation Research, vol. 87, no. 12, pp. 1095-1102, 2000.

[121] B. Ay, A. Iyanoye, G. C. Sieck, Y. S. Prakash, and C. M. Pabelick, "Cyclic nucleotide regulation of store-operated $\mathrm{Ca}^{2+}$ influx in airway smooth muscle," The American Journal of Physiology: Lung Cellular and Molecular Physiology, vol. 290, no. 2, pp. L278-L283, 2006.

[122] H. Harizi, M. Juzan, J.-F. Moreau, and N. Gualde, "Prostaglandins inhibit 5-lipoxygenase-activating protein expression and leukotriene B4 production from dendritic cells via an IL-10dependent mechanism," Journal of Immunology, vol. 170, no. 1, pp. 139-146, 2003.

[123] N. Flamand, M. E. Surette, S. Picard, S. Bourgoin, and P. Borgeat, "Cyclic AMP-mediated inhibition of 5-lipoxygenase translocation and leukotriene biosynthesis in human neutrophils," Molecular Pharmacology, vol. 62, no. 2, pp. 250-256, 2002.

[124] T. Kambayashi, R. P. A. Wallin, and H.-G. Ljunggren, "cAMPelevating agents suppress dendritic cell function," Journal of Leukocyte Biology, vol. 70, no. 6, pp. 903-910, 2001. 


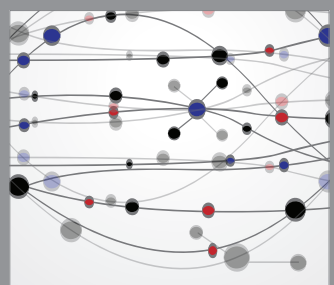

The Scientific World Journal
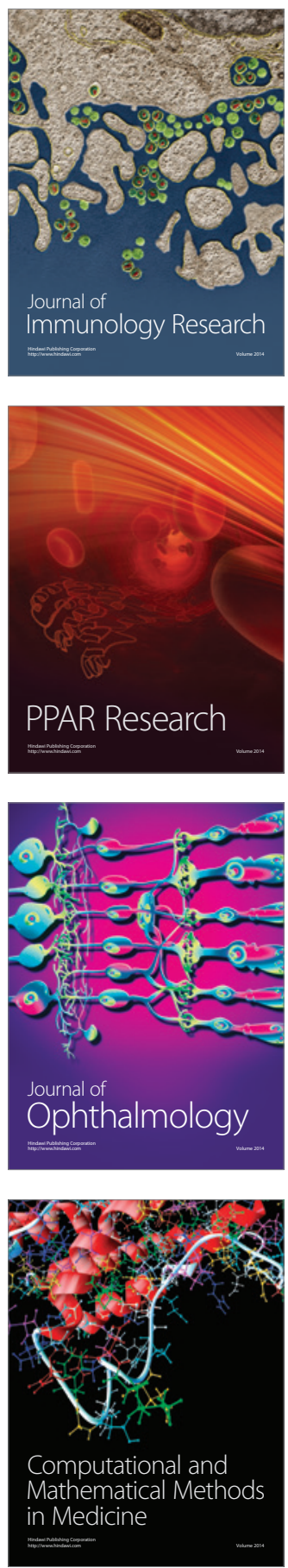

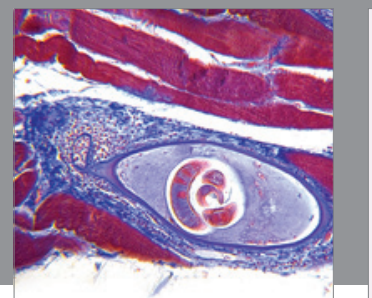

Gastroenterology

Research and Practice
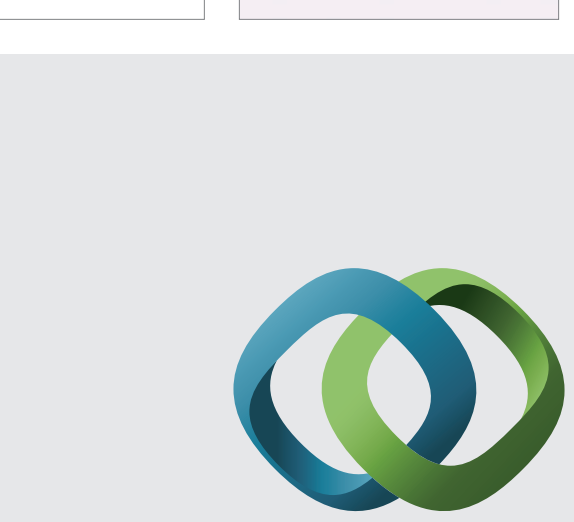

\section{Hindawi}

Submit your manuscripts at

http://www.hindawi.com
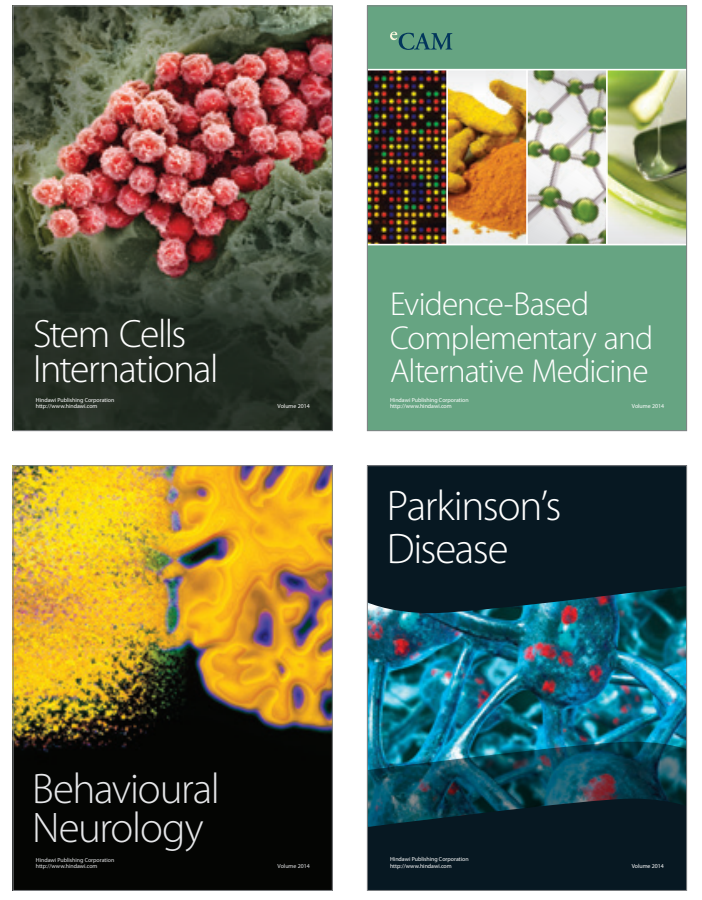
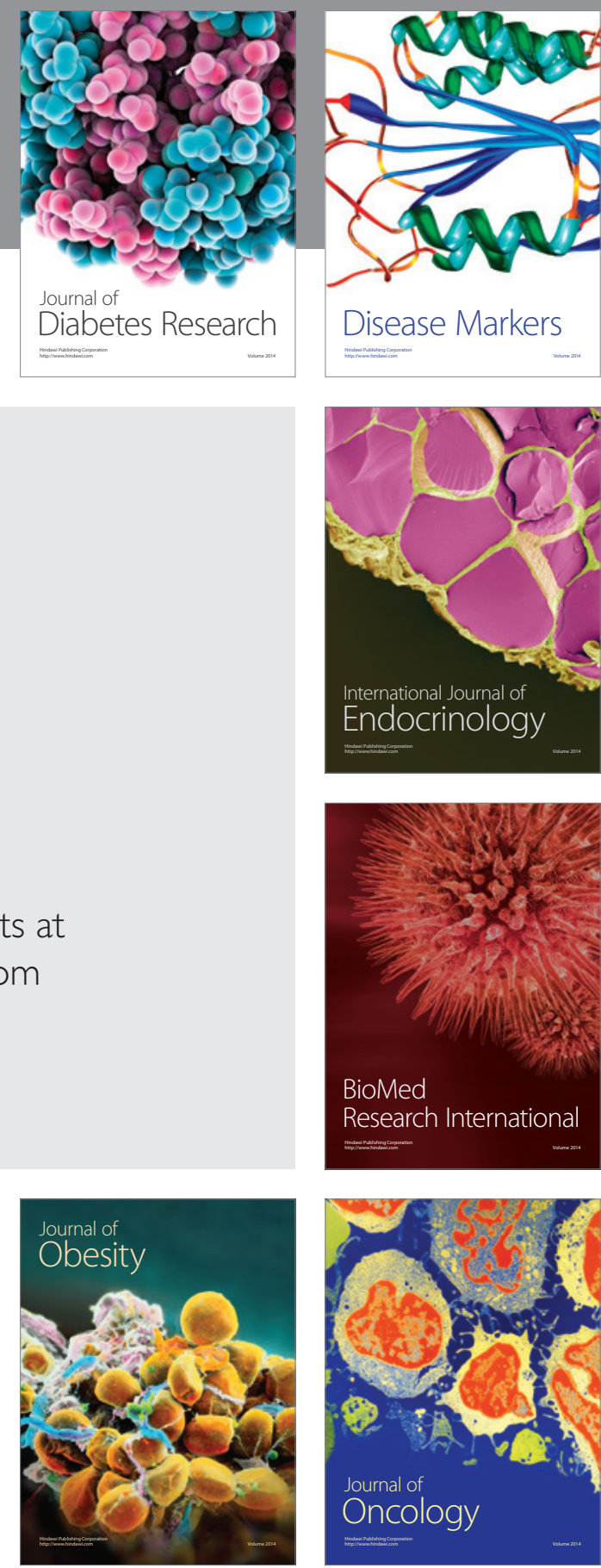

Disease Markers
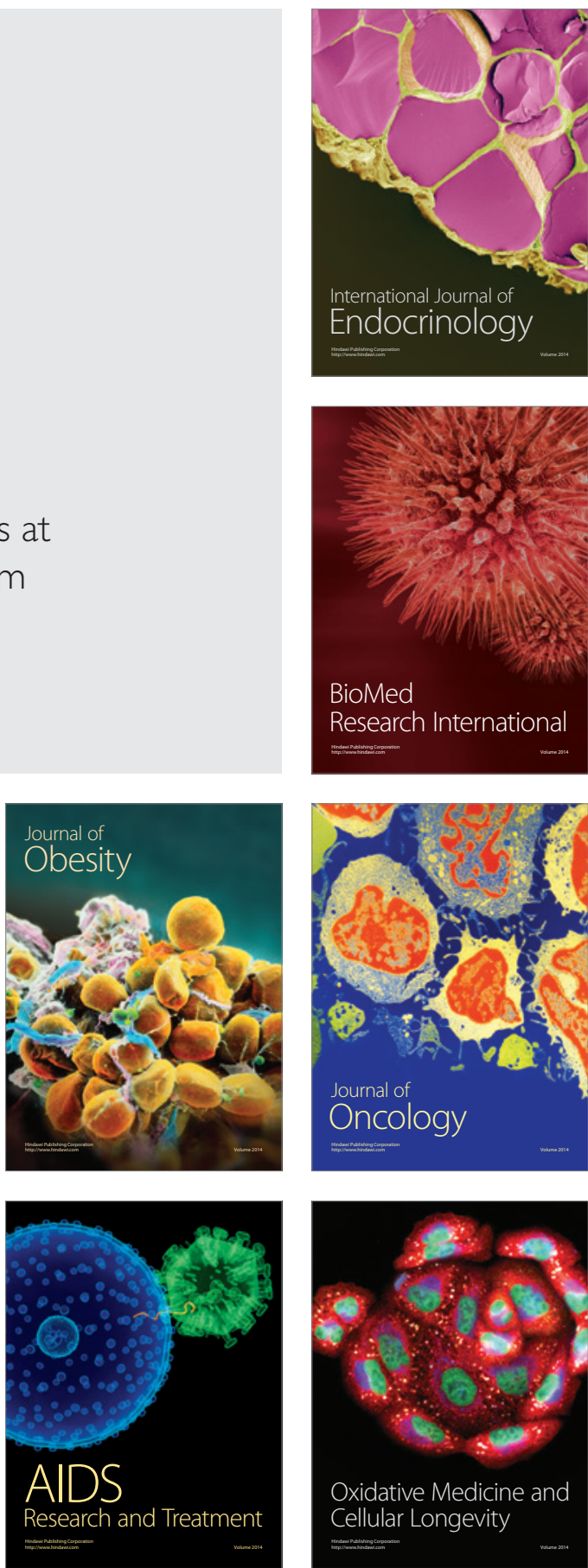